\title{
A NEW HEREDO-FAMILIAL NEUROLOGICAL SYNDROME
}

\author{
BY \\ C. C. HARVEY, J. C. HAWORTH and JOHN LORBER \\ From the Department of Child Health, the University of Sheffield, and the Children's Hospital, Sheffield
}

(RECEIVED FOR PLBLICATION JANLARY 24, 1955)

This report describes a family in which a heredofamilial neurological disorder of unusual type appears to have been transmitted from an affected father to at least five of his children. The main features of the condition consisted of athetosis, hypotonia, absent tendon refiexes, extensor plantar responses, mental retardation and periodic febrile attacks occurring simultaneously in several members of the family with episodes of prolonged unconsciousness.

Ford (1952) gave an account of the various hereditary and familial encephalomyelitic and demyelinating diseases, but none of the clinical syndromes he described correspond with our cases, nor have we been able in a search of the literature to find records of cases similar to our own. We therefore present the following case reports in the belief that they represent a hitherto undescribed disease.

\section{Case Reports}

The family first came to our notice on December 8 , 1948. The mother, a woman of low intelligence, was born in 1915. She has no neurological disorder. She had given birth during her first marriage to four children who are neurologically healthy individuals. After the death of her husband she married a man born in 1904, who since childhood had suffered from a neurological disability, and is considered unable to work. Our only information about his earlier years is that he was late in walking, was mentally backward and had no schooling after the age of 7. In August, 1951, at the age of 47, he was examined by Dr. Sheila Sheehan. He was found to have pes cavus, kyphoscoliosis and severe athetosis which amounted almost to torsion spasm. He had extensor plantar responses, absent tendon reflexes and some wasting of the shoulder girdle muscles. The picture resembled Friedreich's ataxia or some allied heredo-familial disorder, but there was athetosis and there were no cerebellar signs. His family could not be traced. Little is known about them, except that his father and siblings were all well, but his mother had some difficulty in walking.
Case 1. This boy. the first child of the second husband, was born on October 25,1942 . His progress was subnormal throughout. He was examined by a paediatric colleague at the age of $5 \frac{1}{4}$ years on January 26 . 1948, and was found to have choreo-athetosis, with gross mental deficiency. There was no response to intelligence testing and he was certified as a mental defective. His hearing and vision were thought to be normal. On September 11. 1948. at the age of 5 years 11 months he died in a fever hospital of what was reported to be pneumonia following measles. Necropsy showed bilateral bronchopneumonia. The central nervous system was not examined. There was no record of any abnormality in the liver.

At the time of this illness three younger siblings also became ill.

Case 2. The second child of this marriage, a boy, was born on June 8, 1944, weighing $5 \frac{1}{4} \mathrm{lb}$. (2.3 kg.). He grasped objects only at 1 year, was very late sitting up and his mother described him as "shaky" in infancy. Up to the age of 4 years he had never walked more than a few steps without support and had only begun to say single words at $3 \frac{1}{2}$ years.

In September, 1948. when he was $4 \frac{1}{4}$, he developed at the same time as his brother (Case 1) an acute febrile illness with a rash, which was diagnosed as measles. Two days after the appearance of the rash his eyes turned up and he became unconscious but he had no fit. He failed to recognize his mother for a week and his general condition deteriorated. Subsequently, his legs became weaker and he was no longer able to walk, even with support. He became more 'shaky' and 'jumpy' and his speech became more indistinct. When we first examined him on December 18, 1948, three months after his 'measles', he was emaciated, weighing $25 \frac{1}{2} \mathrm{lb}$. $(11 \cdot 5 \mathrm{~kg}$.). The haemoglobin was $55^{\circ}$ o (Sahli). He exhibited generalized athetosis. He did not respond to simple questions and was considered to be mentally retarded. By the age of 6 years he was able to walk with the support of furniture and made some attempt to feed himself. There appeared to be no improvement in his condition during the next two years and he did not attend school.

He was seen in the Children's Hospital, Sheffield, in July, 1951. He then had gross athetosis and was unable 
to stand or walk. It was difficult to assess the tendon reflexes, but they were thought to be present. The plantar responses were flexor and the abdominal reflexes were present. The optic fundi were normal. Intelligence testing was difficult because of the athetosis, but his attention was well held. No accurate figure for his intelligence quotient could be given, but it was thought to be about 50 .

He received physiotherapy and speech therapy with considerable improvement. Subsequently he was admitted to a convalescent home where this treatment was continued, and where he was given suitable schooling for an educationally subnormal child. While he was there he received artane', $1 \mathrm{mg}$. twice daily, for six months without obvious improvement.

His condition was reassessed in August. 1954, at the age of 10 years. His nutrition was good and he was happy and cooperative. He had gross generalized hypotonia, muscular weakness and pronounced athetosis. His speech was intelligible but dysarthric. All tendon reflexes were now absent and the plantar responses were extensor. The upper abdominal reflexes were present but the lower ones absent. The fundi were normal and there were no apparent sensory changes. There were no cerebellar signs. He was barely able to stand unaided

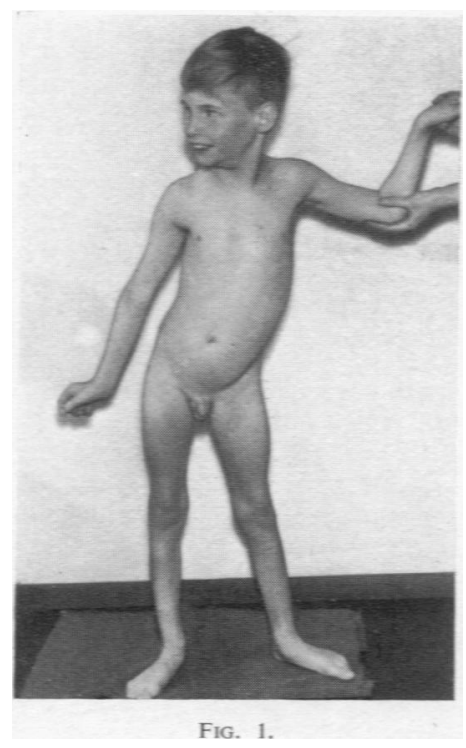
and could not walk (Fig. 1). He had no KayserFleischer rings on slit-lamp examination of his eves.

His intelligence was reassessed (Terman-Merrill) and the I.Q. was 51. He cooperated well. but his physical disability may have been in small part responsible for his low score. An electroencephalogram was normal. Liver function tests, a blood Wassermann reaction and tests for toxoplasmosis gave normal results. There

was no excess of amino-acids in the urine.

Case 3. The third affected child was a girl born at full term on June 3, 1945, weighing $6 \frac{1}{2} \mathrm{lb}$. $(3 \mathrm{~kg}$.) after a normal pregnancy and delivery. She was said to have developed fairly normally at first, sitting unsupported at 8 or 9 months and first walking unaided between 12 and 18 months. She was said to have walked, run and played normally and to have said simple sentences until she developed, in September, 1948, the illness which in her case also was diagnosed as measles. She was then $3 t$ years old. Following this illness she deteriorated mentally and became unable to walk. She was first examined by one of us with her two affected brothers (Cases 2 and 4) on December 8, 1948, at the age of 3 years 6 months. She was as severely malnourished and debilitated as her brothers, and weighed only $25 \frac{3}{4} \mathrm{lb}$. (11.6 kg.). She displayed appreciable athetosis. Two months later her sitting posture was still unsteady, though she had started walking with difficulty. She was using a few simple words. Two years later, in November, 1950 , at the age of $5 \frac{1}{2}$ years, she was using short sentences, but her speech was indistinct. She walked very unsteadily with assistance on a broad base. She had considerable athetosis, especially of the left hand. At $6 \frac{1}{2}$ years of age she was walking unsteadily on her own. In April, 1952, when aged 6 years 10 months, she attended the Sheffield Children's Hospital as an outpatient, when she was found to be considerably mentally retarded, could not walk without support and was said to have only recently acquired control over bowel and bladder. The tendon reflexes in the arms and legs were diminished and the plantar responses were flexor.

On March 26, 1954, another illness struck her and she became ill with a sore throat, red eyes, irritability, anorexia and vomiting (see also Case 4). Two days later she was thought to be feverish and became semicomatose. She was admitted to the Children's Hospital on March 31, 1954. She was then afebrile, comatose and poorly nourished, weighing only $38 \mathrm{lb} .(17 \cdot 1 \mathrm{~kg}$.). She lay on her side in semi-coma with the head extended, the limbs flexed and with occasional athetoid movements of the arms. The muscle tone in the limbs was normal, but no tendon reflexes could be elicited. The left plantar response was extensor and the right flexor. Ocular movements appeared to be full and the fundi were normal. No other abnormality was found and the throat was not inflamed.

The following investigations gave normal results: cerebrospinal fluid, a radiograph of the skull and chest, urine. blood urea and serum proteins. An electroencephalogram (E.E.G.) on April 8, 1954, showed a continuous high-amplitude 1-3 cycle/second activity occurring synchronously in both posterior regions. The record suggested involvement of the diffuse reticular network, probably in the midbrain, or a posterior fossa lesion. (Fig. 2.)

There was little change in the child's general condition over the next few weeks. She always lay on her side with her legs flexed and resented interference. She showed no interest in her surroundings, and feeding was difficult. She was discharged on May 11, 1954, at the mother's request, and by then the athetosis was more pronounced.

She was seen again three months later, when she was fully conscious and cooperative, and had the same neurological features (Fig. 3) as her brother (Case 2). Inspection of the eyes revealed no Kayser-Fleischer rings. A second E.E.G. on September 15, 1954, showed considerable improvement, with residual abnormalities localized to the posterior region on the 


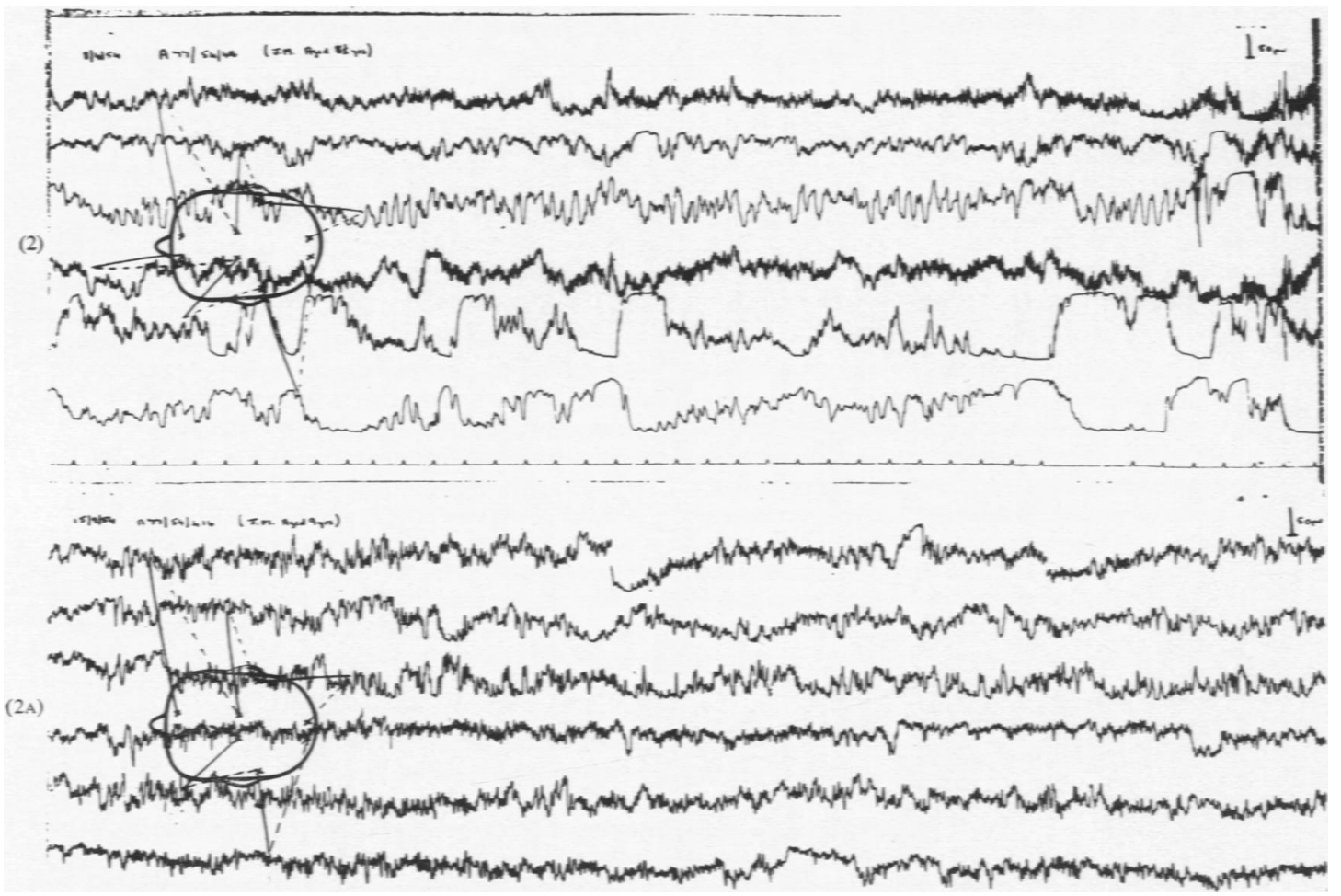

Figs. 2 and 2A.-Upper tracing taken on April 8. 1954. shows almost continuous moderate amplitude 2 c. sec. waves oczurring synchronously in both posterior regions. This is consistent with a posterior fossa lesion.

In the lower tracing taken on September 15, these slow waves have disappeared, and the record now contains an abnormally wide range of frequencies, with an ill-defined, paroxysmal right temporal theta focus. This looks very much like an epileptic interseizure record with possibly a right temporal epileptogenic focus.

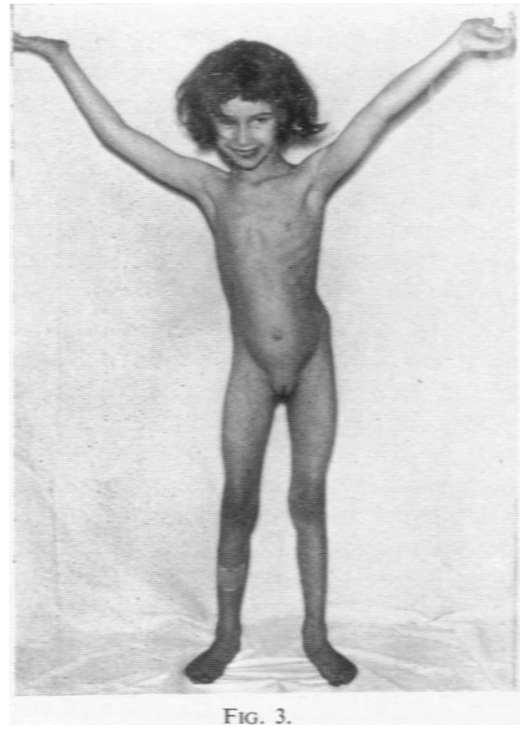

right side (Fig. 2A). The Wassermann reaction and liver function tests also performed about this time were normal. A toxoplasmosis dye test was positive in a titre of 1 in 49 and a complement fixation test was positive at 1 in 4. These results were not thought to be significant.
Case 4. This boy was born at full term on June 8 . 1946, after a normal pregnancy and delivery. He weighed $7 \frac{1}{2} \mathrm{lb}$. $(3.5 \mathrm{~kg}$.). The neonatal period was uneventful. He was said to have walked at 18 months of age, but could never manage stairs. He used simple words at about the age of 2 years.

In September, 1948, when $2 \frac{1}{4}$ years old, at the same time as his siblings (Cases 1, 2 and 3,) he developed a febrile illness with a rash. He was unconscious for an unknown period. When examined on December 8, 1948 , at the age of $2 \frac{1}{2}$ years, he was very wasted and weighed $22 \mathrm{lb} .6 \mathrm{oz}$. (10 kg.). Neurological examination proved impracticable owing to his struggling. Two months later, he could stand holding the furniture, with the same unsteady, wobbling posture as the other children. At the age of 5 years he could only walk if supported, was unable to feed himself with a spoon and was incontinent. He was dysarthric and could only make three-word sentences. In August, 1951, when seen as an out-patient at Sheffield Children's Hospital, the abnormalities noted were general mental retardation, inability to walk unaided and diminution of the tendon reflexes. Six months later his plantar responses were 
found to be extensor. At the age of 6 years, on Julv 22, 1952 , he was unsteady and had athetosis, but less grossly than the older children. After that he is reported to have begun walking with support and talking more freely. His progress was then checked severely by a febrile illness, with sore throat, in April and May, 1953, during which he was in bed for seven weeks. His sister (Case 5) had a similar illness at the same time. Subsequently he could neither sit nor stand nor talk. When his two sisters (Cases 3 and 5) were admitted with the third acute family illness in March and April, 1954, though this boy was not seen at this hospital, the mother stated that he had had a similar illness with red eyes, sore throat, flushed cheeks and vomiting. His eyes rolled up, his arms were rigidly flexed, he failed to recognize his parents and could not swallow. He regained consciousness in about a week. The parents were unwilling for him to be admitted to hospital.

He was seen

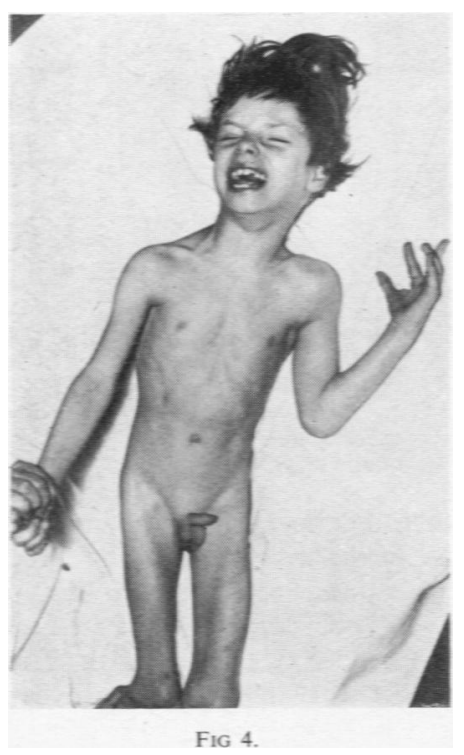
again on August 25 , 1954, when his general condition was found to be poor. He was conscious, wasted, hypotonic and was unable to sit or stand. Tendon reflexes were absent and the plantar responses were extensor (Fig. 4). Inspection of his eyes s howed no Kayser - Fleischer rings. There was athetosis and he had a left internal strabismus. His blood Wassermann reaction, liver function tests and tests for toxoplasmosis all gave normal results. His E.E.G. was normal.

Case 5. The next affected child was a girl born at term on February 15, 1952, weighing 7 f. $14 \mathrm{oz}$. (3.65 kg.). She was seen regularly at the baby clinic in the Sheffield Children's Hospital for the first year of life, and developed normally. She smiled at 6 weeks, pulled herself to the sitting position at 7 months and said single words at 11 months. She could shuffle across the floor at about 1 year of age. At 14 months of age, at the same time as her brother (Case 4), she had an acute illness, described as a 'sore throat', for which she was kept in a fever hospital for six weeks. 'Cerebral irritation' was noted: the cerebrospinal fluid was examined and was found to be normal. Two months after the onset of this illness she was seen again at the Children's Hospital and it was noted that she was very hypotonic, could no longer sit, crawl or pull herself into the standing position which she had previously been able to do. Her weight had been stationary for 5 months. She had a squint but no other neurological signs. After this she became able to sit unsupported, pulled herself up to stand and said individual words, but could not make sentences and could not walk.

She was not seen again until she was admitted to hospital on April 3, 1954, at the age of 2 years 1 month. with a similar history to Cases 3 and 4, namely, red eyes, sore throat and vomiting. Her eyes had rolled up and she had had twitching of the limbs at 15-minute intervals. followed by unconsciousness. Her mother said that this illness was very similar to the one she had had 11 months earlier.

On admission she was stuporose, but responded to painful stimuli and lay with the legs flexed. Her temperature was $100 \cdot 4^{\circ} \mathrm{F}$., rising to $104 \cdot 2^{=} \mathrm{F}$. The pupils were equal and reacted to light. The fundi were normal. There were no cranial nerve lesions, but she had a concomitant squint. There was no meningism. All limbs moved well but were hypotonic and no tendon reflexes could be elicited. The plantar responses were doubtful. Nothing abnormal was found in any other system.

INVESTIGATIONS. The cerebrospinal fluid was normal. including the Wassermann reaction and Lange curve.

The urine was normal, and an amino-acid chromatogram (April 8, 1954) was normal, apart from a possible slight excess of cystine. No reducing substance or phenyl-pyruvic acid was found.

The haemoglobin was $12 \mathrm{~g}$. $100 \mathrm{ml}$. with a leucocyte count of $13,000 \mathrm{c} . \mathrm{mm} .172^{\circ}$ 。 neutrophil polymorphs, $24^{\circ}{ }_{0}$ lymphocytes, $4^{\circ}{ }_{0}$ monocytes). The blood urea, sugar and potassium levels were within normal limits.

Liver function tests were within normal limits.

The Wassermann reaction (blood) was negative.

The serum proteins were: albumin $3 \cdot 1 \mathrm{~g} .100 \mathrm{ml}$., globulin $2 \cdot 8$ g. $100 \mathrm{ml}$.

A blood culture $(x 4)$ was sterile.

Clinical Course and Treatmext. The degree of consciousness did not alter significantly during the five weeks that she was in hospital. Following admission. because it was at first thought likely that she might have an acute bacterial infection, she was treated with penicillin and streptomycin. The temperature slowly fell to normal over a period of seven days. When the antibiotics were discontinued four days later there was a sudden rise in temperature to $104 \cdot 4^{\circ} \mathrm{F}$. without apparent cause. As pulmonary complications were feared because of her prolonged coma, penicillin treatment was restarted and continued while she was in hospital. The temperature again settled and she remained afebrile. The plantar responses were found to be extensor on April 6, 1954, but the tendon reflexes remained absent. A week later she developed obvious athetoid movements for the first time. From then onwards her general condition did not alter. 


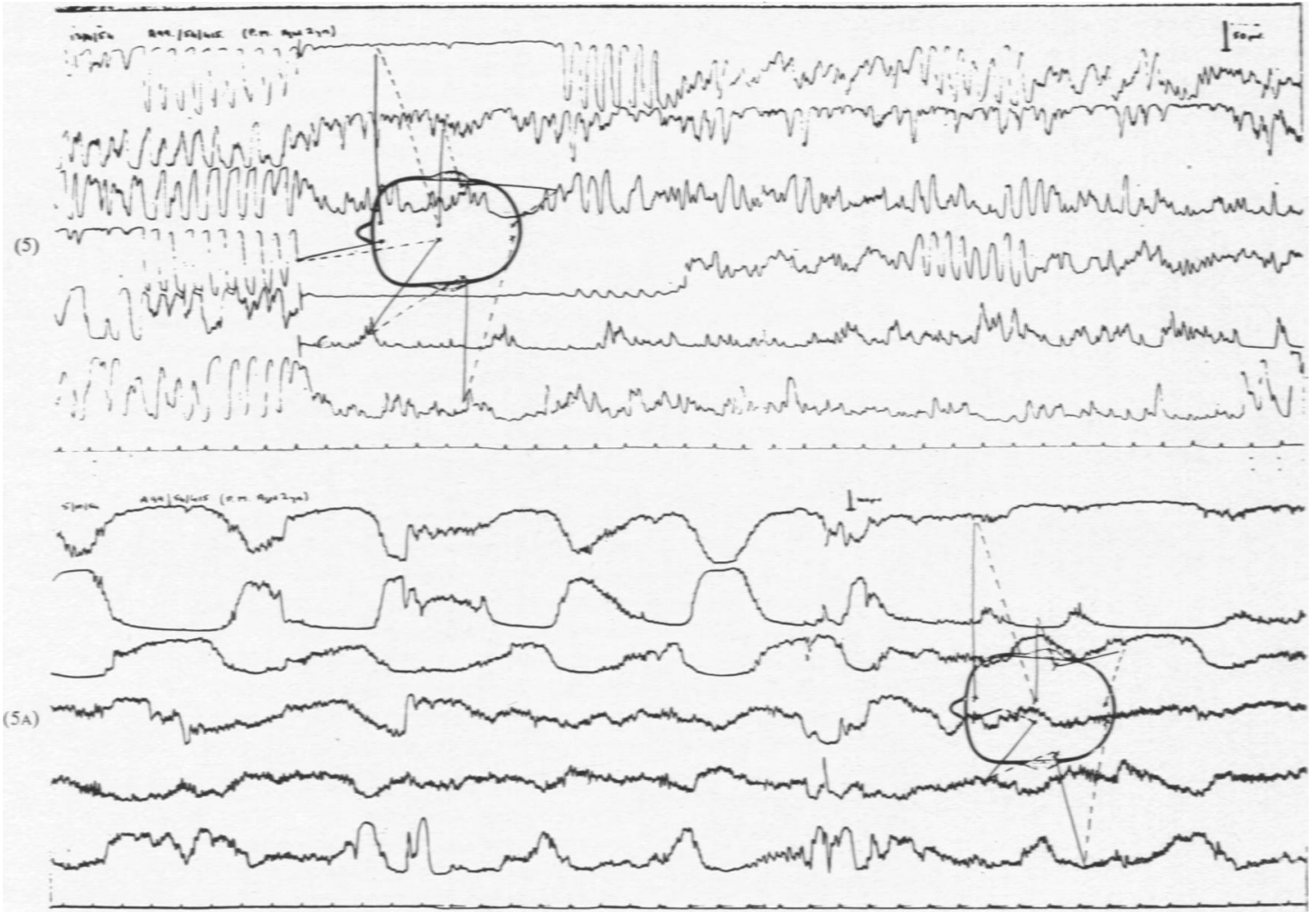

FIGS. 5 and 5A.-Upper tracing taken on April 13, 1954, shows generalized bursts of high amplitude 1 t $-2 \mathrm{c}$ sec. waves occurring synchronously in all areas. suggesting involvement of the structures around the third ventricle or of the mid-brain.

In the lower tracing taken on October 5, 1954, these bursts of high amplitude slow waves have disappeared and the record is normal for her age.

An electro-encephalogram was performed on April 13, 1954, and was described as follows:

-There are frequent bursts of extremely high amplitude, generalized 2 cycles second waves occurring synchronously in all areas. This suggests a lesion involving the reticular network, probably in the midbrain' (Fig. 5).

An air encephalogram on April 23. 1954, showed no gross hydrocephalus, but there was some widening of the sulci on the surface of the brain.

On May 11, 1954. she was sent home with her sister (Case 3).

She was seen again at her home on August 24, 1954. Her general condition had scarcely altered and she lived a vegetative existence. The physical signs had not changed. In October. 1954, she was more conscious. She had no Kayser-Fleischer rings. A second E.E.G. was perforned and was found to be normal (Fig. 5A).

\section{Summary of Case Reports}

These five children all showed the same type of clinical syndrome and this in turn was similar to that of their father. It appears likely that three of them were of approximately normal physical and mental development in early infancy, but subsequently deteriorated and this deterioration was in four cases known to be preceded by acute febrile illnesses. There were three such known acute episodes in the family. The first in 1948 affected all four of the children then living (Cases 1-4). The second in 1953 affected two of the four then living children (Cases 4 and 5), and the third in 1954 affected three of the four children (Cases 3, 4 and 5); the remaining child (Case 2) was not then living at home. All of these episodes were of considerable severity and the first led to the death of one child (Case 1). Most of the others were associated with prolonged unconsciousness. Each child developed athetosis. In one (Case 1) we do not know of an acute febrile illness preceding it; in another (Case 2) athetosis was present after the first known febrile episode, but he may have had athetosis before that time before he came under our observation. The last three did not have athetosis until after one of these febrile episodes. There was severe mental deterioration immediately following each of the febrile episodes which we were able to observe, and there was a tendency for subsequent mental and 
physical improvement until the onset of the next febrile episode. There was no progressive deterioration in any of the children under our observation. In those children whom we observed before these episodes there was no apparent hypotonia or abnormality of the reflexes, but every one of the survivors became grossly hypotonic with loss of deep tendon reflexes and with extensor plantar responses. There was no apparent sensory loss.

The only investigations which yielded significant results were the electroencephalograms. In Cases 2 and 4, E.E.G.s were only done long after one of these acute episodes and were reported to be within normal limits. In Case 3 the E.E.G. during her last febrile episode was grossly abnormal, suggesting damage to the midbrain. Five months later, however, concurrent with much clinical improvement, her E.E.G. had almost returned to normal. In Case 5 the E.E.G., during her acute illness in 1954, showed exactly the same abnormalities as in Case 3. Six months later, after much clinical improvement, her E.E.G. became normal. Other investigations (liver function tests, urinary amino-acid chromatograms, C.S.F., Wassermann reaction, air encephalography and toxoplasmosis tests) were all noncontributory in those children in whom they were performed.

The mother had three other pregnancies during her second marriage. A boy, born two years after Case 4, on July 8, 1948, was first seen in the group examined on December 8, 1948, when he appeared to be a healthy, bottle-fed baby. He later began walking and talking at the average age. No abnormalities were detected when 3,4 and 5 years of age, and he entered school normally when 5 years old. During the third acute family illness, in April, 1954, he became ill with a cold and fever, shortly after his two sisters, Cases 3 and 5, and his brother, Case 4. He was admitted to the Sheffield Children's Hospital. No neurological abnormalities were found; an electroencephalogram was normal and he made a rapid recovery. He appeared to be a healthy, normal child at re-examination in August, 1954.

The mother next had a still-birth in 1950. and then a premature boy weighing $4 \mathrm{lb}$. $15 \mathrm{oz}$., delivered by Caesarean section on February 25, 1951. This baby died at home at the age of 11 weeks, on May 10 , 1951, from 'pneumonia', of which we have no details.

\section{Discussion}

The histories of our patients are, through domestic circumstances, not as complete as we would have liked.
It seems to us that the illnesses of our patients can be divided into two stages: (1) An underlying heredo-familial neurological disorder affecting the father and at least five children; (2) superadded acute episodes with unconsciousness.

The nature of these acute episodes is a matter of speculation. We did not see any of the children during their acute illness in 1948 , nor do we know if any earlier episodes occurred. During the episodes that we observed in 1954 the early symptoms and signs were very suggestive of the prodromal stage of measles, but it appears likely that the illnesses in 1948 and 1953 were of a similar nature and were not in fact measles. In 1948, however, the children were reported to have had a rash, but no rash was present in the more recent episodes. The severe disturbance of consciousness which lasted for several months in one surviving child, and the type of neurological residua, are unlike those of measles encephalitis. It is possible that these episodes were acute exacerbations of a demyelinating process. It is perhaps more likely, however, in view of the apparent infectivity of the illnesses, since several children were affected at the same time, that they were attacks of encephalomyelitis, possibly of virus origin, superimposed upon an already abnormal and unusually susceptible nervous system. A virus might cause this disturbance either by direct invasion of the nervous system or by an allergic or anaphylactoid reaction, such as that which may be responsible for the post-infective encephalitides (Ferraro, 1944). The absence of a pleocytosis in the cerebrospinal fluid of Cases 3 and 5 during the acute stage would seem to make a direct viral invasion less likely. This hypothesis might explain why the normal child, born in 1948, without the basic heredofamilial nervous disorder, did not develop neurological sequelae in the 1954 illness. As the nervous system was not examined at necropsy in our one fatal case (Case 1) the above explanation is pure conjecture.

The gross abnormality of the E.E.G.s in an acute phase of the illness in Cases 3 and 5 , the subsequent return of the E.E.G.s to approximately normal after recovery, and the normal E.E.G.s after the acute stage in Cases 2 and 4 suggest that the acute febrile episodes were affections of the brain, and not nonspecific infections which led to clinical deterioration merely by their debilitating effect.

According to Miller and Evans (1953) recurrence of post-infective acute disseminated encephalomyelitis is almost unknown, and in the rare instances of recurrence it may follow other exanthems or minor non-specific infections, usually of the upper respiratory tract, as a result of which 
lasting immunity does not develop. Miller and Gibbons (1954) described recurring encephalomyelitis in three children in the same family, most of the episodes being precipitated by upper respiratory infections. One of the children, a boy of 14, had as many as six encephalitic episodes during a period of eight months. All three children, however, unlike our cases, were eventually left free of neurological sequelae. These authors postulated an anaphylactoid hypersensitivity to an infecting virus in the upper respiratory tract as the cause of their neurological episodes, and the fact that several of the episodes responded to A.C.T.H. supported their hypothesis.

Hepato-lenticular degeneration may affect several siblings and its course may be punctuated with episodes of coma. The points against such a diagnosis in our cases were that the father was also similarly affected, that no cirrhosis of the liver was noted at necropsy of Case 1, that no abnormal amino-aciduria was demonstrated in two of our cases (Nos. 2 and 5), that the liver function tests were normal in all four living children, that none of our cases had Kayser-Fleischer rings, and finally, the prolonged course of the disease.

Tinel and Badonnel (1934) reported two brothers in a family of three children with normal parents, who, after normal development until 14 months of age, both developed, at the same chronological age but not simultaneously, a neurological illness. The first child had convulsions, and this was followed four months later by blindness and optic atrophy. At $2 \frac{1}{2}$ years of age he had measles or German measles with subsequent wasting of the limbs, inability to walk, equinus deformity of the feet, scanning speech, horizontal nystagmus, and intention tremor. He became an idiot with spastic paraplegia and absent ankle jerks. The cerebrospinal fluid was normal at an unspecified stage of the disease. The second child was normal until 14 months and then developed vertical nystagmus. At 18 months he had fairly severe measles or German measles, and this was followed by rapidly progressive blindness, wasting of the legs and increasing mental retardation. The cerebrospinal fluid was normal. The final outcome was similar to that of his elder brother, namely, idiocy, spastic paraplegia, cerebellar syndrome, wasting of the muscles of the lower limbs, with absent ankle jerks, and blindness. The history of these two children is somewhat similar to our cases, but the neurological syndrome is quite unlike that which developed in our patients.

\section{Summary}

A new heredo-familial neurological disorder affecting a father and five of his children is described with detailed case histories of each. The main features of the condition consisted of athetosis, hypotonia, absent tendon reflexes, extensor plantar responses, mental retardation and periodic febrile attacks occurring in several members of the family with episodes of prolonged unconsciousness.

The possible aetiology of the condition is discussed, and familial recurrent encephalitic illnesses reported in the literature have been reviewed.

We thank Professor R. S. Illingworth and Dr. T. Colver for permission to study their cases: Professor $\mathbf{R}$. S. Illingworth and Sir Charles Symonds for their helpful criticism; Dr. C. E. Dent and Dr. H. Bickel for the aminoacid chromatograms; Dr. J. W. Warboys for the electroencephalograms; Professor C. P. Beattie and Dr. J. K. A. Beverley for serological tests; Mr. G. P. Elphick for examining the eyes of Case 2, and Dr. T. E. D. Beavan for his permission to use the notes of his examination of Cases 1 and 2 before they came under our observation: and Dr. J. Main Russell who, as Divisional Medical Officer of Health, afforded us many contacts with the family.

\section{REFERENCES}

Ford. F. R. (1952). Diseases of the Nervous System in Infancy. Childhood and Adolescence. 3rd ed. Oxford.

Ferraro. A. (1944). Arch. Neurol. Psychiat.. Chicago, 52. 443. Miller. H. G. and Evans. M. J. (1953). Quart. J. Med.. 22 (N.S.). 347. 1 and Gibbons. J. L. (1954). Ann. intern. Med. 40.755.

Tinel. J. and Badonnel (1934). Rev. neurol.. Paris, 1. 373. 